Research Article

\title{
Evaluation of Zenith Tropospheric Delay Derived from Ray-Traced VMF3 Product over the West African Region Using GNSS Observations
}

\author{
Samuel Osah $\mathbb{D}^{\mathrm{D}}$, Akwasi A. Acheampong ${ }^{\mathbb{D}}$, Collins Fosu, and Isaac Dadzie \\ Department of Geomatic Engineering, College of Engineering, Kwame Nkrumah University of Science and Technology, Kumasi, \\ Ghana
}

Correspondence should be addressed to Samuel Osah; osahsamuel@yahoo.ca

Received 1 September 2020; Accepted 19 February 2021; Published 27 February 2021

Academic Editor: Stefania Bonafoni

Copyright (C) 2021 Samuel Osah et al. This is an open access article distributed under the Creative Commons Attribution License, which permits unrestricted use, distribution, and reproduction in any medium, provided the original work is properly cited.

The growing demand for Global Navigation Satellite System (GNSS) technology has necessitated the establishment of a vast and ever-growing network of International GNSS Service (IGS) tracking stations worldwide. The IGS provides highly accurate and highly reliable daily time-series Zenith Tropospheric Delay (ZTD) products using data from the member sites towards the use of GNSS for precise geodetic, climatological, and meteorological applications. However, if for reasons like poor internet connectivity, equipment failure, and power outages, the IGS station is inaccessible or malfunctioning, and gaps are created in the data archive resulting in degrading the quality of the ZTD and precipitable water vapour (PWV) estimation. To address this challenge as a means of providing an alternative data source to improve the continuous availability of ZTD data and as a backup data in the event that the IGS site data are missing or unavailable in West Africa, this paper compares the sitewise operational Vienna Mapping Functions 3 (VMF3) ZTD product with the IGS final ZTD product over five IGS stations in West Africa. Eight different statistical evaluation metrics, such as the mean bias (MB), mean absolute error (MAE), root mean squared error (RMSE), Pearson correlation coefficient $(r)$, coefficient of determination $\left(r^{2}\right)$, refined index of agreement $\left(\mathrm{IA}_{\mathrm{r}}\right)$, Nash-Sutcliffe coefficient of efficiency (NSE), and the fraction of prediction within a factor of two (FAC2), are employed to determine the degree of agreement between the VMF3 and IGS tropospheric products. The results show that the VMF3-ZTD product performed excellently and matches very well with the IGS final ZTD product with an average MB, MAE, RMSE, $r, r^{2}, \mathrm{NSE}, \mathrm{IA}_{\mathrm{r}}$, and FAC2 of $0.38 \mathrm{~cm}, 0.87 \mathrm{~cm}$, $1.11 \mathrm{~cm}, 0.988,0.976,0.967,0.992$, and $1.00(100 \%)$, respectively. This result is an indication that the VMF3-ZTD product is accurate enough to be used as an alternative source of ZTD data to augment the IGS final ZTD product for positioning and meteorological applications in West Africa.

\section{Introduction}

The impact of the Earth's neutral atmosphere on GNSS signals has become a major concern in GNSS Positioning, Navigation, and Timing (PNT) applications. GNSS signals experience bending and delay due to variations in refractivity along the signal transmission path, which increases the signal path length travelled more than the actual geometric distance between the satellite in view and the receiver $[1,2]$. This introduces an error in the measured range and degrades the positioning accuracy, particularly the vertical component [3].
The influence of the troposphere on GNSS signals ranges from about 2.0 to $2.6 \mathrm{~m}$ in the zenith direction to about 20 to $28 \mathrm{~m}$ near the horizon and at lower elevation angles [4]. The fact that tropospheric delay cannot be removed by a combination of dual or multifrequency GNSS observations owing to its nondispersive nature unlike the ionospheric delay, and the tropospheric delay is considered as the major error source in GNSS applications and, therefore, remains a major challenge and a growing concern to GNSS users. Precise modelling and/or mitigation is therefore required for precise positioning and navigational applications. Moreover, precise estimates of tropospheric delay can as well be utilised 
to infer precipitable water vapour (PWV) in the atmosphere with high spatial and temporal resolution $[5,6]$. Information about the retrieved PWV is essential for numerical weather prediction (NWP) such as weather forecasts and nowcasting, climate change research, and other atmospheric studies [7-10].

With the growing demand of GNSS technology, a dense network of permanent and continuously operating IGS tracking stations have been established and deployed worldwide towards the use of GNSS for precise geodetic, climatological, and meteorological applications. Due to the high inhomogeneous spatial and temporal variation in water vapour content in the atmosphere, precise modelling of tropospheric delay has been a major challenge to researchers in the GNSS community [11]. For this reason, several approaches and models have evolved over the years towards the quantification and mitigation of tropospheric delay [8]. The models are categorised into surface meteorological parameter-dependent models [12-14] and user location and time-dependent models [15-17].

The IGS is also committed to providing, among other products, high-quality continuous daily time-series ZTD for all IGS ground sites, estimated using precise point positioning (PPP) technique coupled with IGS precise orbit and clock corrections, and observational data in RINEX format generated by each IGS site [18]. The quality of the IGS-ZTD estimation depends on the quality and continuous daily availability of observational data from the various IGS stations [18]. However, if for some reasons such as poor internet connectivity, equipment failure, and electric power outages [19], the IGS sites are inaccessible or absent, gaps are created in the observational data archive owing to inconsistency in data streaming, and the quality of the tropospheric delay estimation is degraded [20], which subsequently inhibits the quality and continuous retrieval of the PWV by the IGS sites.

West Africa, due to its geographic location, is highly vulnerable to the impacts of climate change, global warming, and climate variability [21]. According to [22], the West African Monsoon (WAM) system has been an important area of research in recent decades, as this was driven by the need to understand the mechanisms related to climate variability (intraseasonal and interannual variability) and severe droughts in West Africa. To improve the understanding and predictability of the WAM system in terms of its physical and chemical processes, the African Monsoon Multidisciplinary Analysis (AMMA) project was created. One of the main priorities of the AMMA project is to model and examine the influence of the atmospheric water cycle/ circulation patterns (spatiotemporal variability), so as to better predict its impact on weather and climate in West Africa [23]. Recently, GNSS technology through the concept of GNSS meteorology $[5,6]$ has proven to play a critical role in monitoring climate change and weather studies [19] as previously indicated. In relation to [24], GNSS has the potential of detecting and tracking extreme weather changes such as thunderstorms. Moreover, as stated in [19], the spatiotemporal characteristics of climate weather and its processes can be well studied using GNSS-ZTD since this is an important parameter of the atmosphere. The potential of GNSS observations for retrieving tropospheric water vapour in Africa for meteorological applications has been demonstrated in several studies, some as a means of advancing the course of the AMMA project in Africa. Walpersdorf et al. [23] assess the availability and quality of GNSS data from the IGS tracking stations in Africa for meteorological applications (first obtaining ZTD from which PWV can be inferred from) for use in the AMMA project. Isioye et al. [24] likewise evaluated the potential for observing the African weather with GNSS remote sensing. The study assessed the status of existing GNSS reference networks in the African region for meteorological applications. Bock et al. [22] also observed the WAM with ground-based GNSS receivers as part of the AMMA project. PWV data retrieved from GNSS-ZTD were evaluated against NWP models and radiosonde humidity data. The study revealed the great potential of using GNSS to investigate many atmospheric processes of the WAM. The authors in [25] worked on the preliminary study of GNSS meteorology techniques in Algeria. The study proposed a weighted mean temperature (Tm) model (AWMTE: Algerian weighted mean temperature equation) for the retrieval of PWV in Algeria. Pottiaux et al. [26] performed a comparative study of PWV estimated from GNSS observations using radiosondes and ERA-interim data in Algeria. The results showed the promising potential of GNSS for meteorological applications in Algeria. Isioye et al. [27] likewise investigated the performance of GNSS-derived PWV with PWV retrieved from Atmospheric Infrared Sounder (AIRS) and ERA-Interim data from Nigeria. The results showed that GNSS-PWV provides a useful source of humidity information which can be utilised to improve the water cycle in numeric weather models (NWMs) for various applications in Nigeria. Furthermore, as means of enhancing PWV retrieval from GNSS ground-based receivers in West Africa, Isioye et al. [28] developed three regional Tm models (NWMTE-I, II, and III: Nigerian weighted mean temperature equation) based on datasets obtained from the United States National Centres for Environmental Prediction (NCEP) or National Centre for Atmospheric Research (NCAR) reanalysis II and radiosondes within the West African region. The study recommended NWMTE-III for users in Nigeria, while NWMTE-II for users in the West African region. Interestingly, for the first time in Ghana, Acheampong et al. [29] comparatively studied PWV estimation using GNSS observations in Ghana and datasets from ERA-Interim and NCEP reanalysis. The study demonstrated that PWV can be obtained with high precision from GNSS signals in Ghana. Additionally, the authors in [30] studied the application of prediction models (regression and time-series) for predicting GNSS-PWV over four IGS stations in West Africa. The study reported the quadratic and autoregression models as the most appropriate regression and time-series models, respectively, for the prediction of PWV in West Africa. Ssenyunzi et al. [19] evaluated the accuracy and variability of GNSS-derived ZTD over 4 countries (Uganda, Kenya, Tanzania, and Rwanda) within the East African tropical region using data collected from 5 IGS stations, 4 Africa Array stations, and 4 Malawi Rifting 
stations. The experimental results did indicate that GNSSderived ZTD can be assimilated into NWP models for meteorological applications in the East African region. Ssenyunzi et al. [31] assessed the performance of ERA5 data in retrieving PWV over East African tropical region.

All of these studies suggest that GNSS-derived ZTD may be useful for improving the amount of water vapour retrieval from the atmosphere for meteorological applications in African and for the study and monitoring of the West African Monsoons. However, on account of [23, 24], there are no observations of water vapour in Africa, as there are no operational GNSS networks for GNSS meteorology. Thus, a significant increase in the number of GNSS stations in Africa (which can be done by utilizing the existing permanent GNSS stations and installing new ones) is very important. In line with [22-24], continuous time-series observations from these GNSS stations provide continuous PWV retrieval, an important tool for studying and monitoring the total atmospheric humidity, which is a significant component of the water cycle and associated atmospheric processes (such as convection and precipitation) that are of key importance in the WAM system and the AMMA project at large. Hence, a better understanding of climate and weather patterns requires more comprehensive datasets. Nonetheless, the African IGS stations, apart from being limited in number, are also noted for having large data gaps [23,24,31], as shown in Figure 1, and hence lack providing continuous daily timeseries data which is resourceful and adequate to provide high spatial and temporal resolution ZTD data for precise positioning and meteorological applications in the region [32]. Data gaps associated with African GNSS/IGS stations remain a major concern, and therefore, the need to investigate alternative methods for predicting ZTD to augment/improve the continuous availability of ZTD data at the IGS stations in West Africa is very crucial since the studies discussed above were unable to address or offer alternative solutions to this problem.

In recent years, numeric weather prediction (NWP) reanalysis data have been used to retrieve ZTD by many research institutes as a means of improving space geodetic techniques such as GNSS [33]. One such institution is the Vienna Mapping Functions (VMFs) service, formally the Global Geodetic Observing System (GGOS) atmosphere project developed at TU Wien. The VMF service, among other products, provides daily continuous time-series sitespecific ray-traced zenith tropospheric delay (VMF3-ZTD) products, derived from the European Centre for MediumRange Weather Forecasts (ECMWF) ERA-Interim reanalysis data with a temporal resolution of 6 hours daily and at four epochs $(00,06,12$, and 18 UT) for IGS stations around the world. This product can be used to improve the accuracy of GNSS positioning and retrieval of water vapour for meteorological applications $[17,33]$.

This paper aimed at comparing and evaluating extensively the performance of the site-specific VMF3-ZTD product for IGS stations with the IGS final ZTD product in West Africa using eight different statistical evaluation metrics with the purpose of assessing its suitability and applicability for use as follows: (i) A backup data in the event that the IGS-ZTD data is inaccessible at the IGS tracking stations in West Africa, as a means of improving continuous data availability.

(ii) An additional ZTD data source for estimating PWV that can help improve continuous observations of water vapour in West Africa for meteorological applications and scientific investigations such as improving climate models to better understand the impact of climate change in the region, which will ultimately have a direct impact on agriculture, water resources, and energy.

This study will go a long way towards addressing data gap issues with the West African IGS stations and also enhance research on GNSS and meteorological applications in the region.

Quite a limited number of studies have been conducted in recent years to evaluate the performance of VMF-ZTD or GGOS-ZTD products. The authors in $[34,35]$ evaluated and analysed the global precision and accuracy of the GGOS-ZTD grid products and its application in PPP. Compared with the IGS-ZTD data, the results showed that a mean bias of (2017: $-0.54 \mathrm{~cm}, 2018:-0.57 \mathrm{~cm})$ and a mean RMS of $(2017: 1.31 \mathrm{~cm}$, 2018: $1.83 \mathrm{~cm}$ ) were accurate enough for real-time positioning and navigational applications. Li et al. [36] also assessed the performance of the GGOS-ZTD grid products over China against the IGS-ZTD products. The results did indicate that a mean bias of $-0.40 \mathrm{~cm}$ and a mean RMS of $2.30 \mathrm{~cm}$ were sufficient for ZTD correction and model establishment for GNSS positioning and navigational applications in China. Yuan et al. [37] evaluated the forecast VMF1 (VMF1-FC) gridded data for real-time tropospheric delay modelling in GNSS. The study investigated the performance of the VMF1FC model in terms of its ZHD, ZWD, and mapping functions compared to the empirical models, global pressure and temperature 2 (GPT2), and GPT2 wet (GPT2w) using 28 global IGS stations over a period of 70 days in a PPP context. The results showed that the VMF1-FC model outperformed the GPT2 and GPT2 $w$ models and recommended its implementation in real-time GNSS applications for modelling tropospheric delays. Putri et al. [38] assessed the performance of VMF3-mapping function for GNSS stations in Indonesia using PPP. Compared to VMF1 mapping function and Global Mapping Function (GMF), the results showed comparable performance for the VMF3 and VMF1 mapping functions. The study recommended the use of VMF1 and VMF3 as mapping function models in Indonesia for PPP applications. Nevertheless, these assessments were made on the basis of the VMF1 grid product and the VMF3-mapping function, but no assessment of the VMF3-ZTD site-specific product has been carried out for IGS stations, particularly in the West African region.

\section{Tropospheric Delay}

The troposphere forms the lower portion of the neutral atmospheric layer up to around $50 \mathrm{~km}$ [39]. The effect of the troposphere on GNSS signals is called tropospheric delay, 


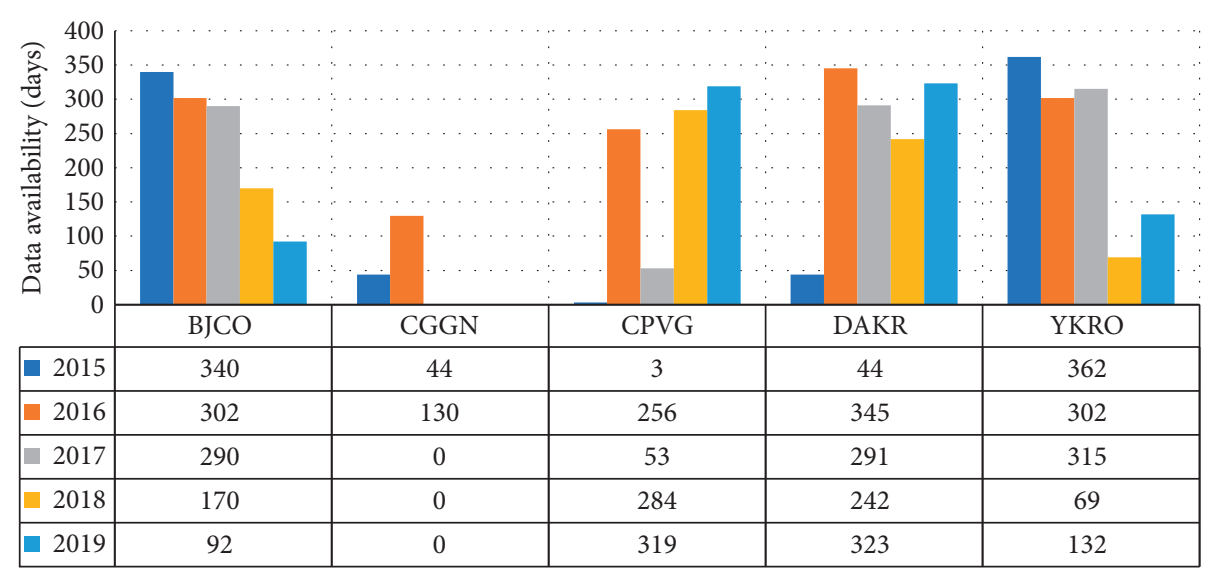

Figure 1: Data availability (in days) for the IGS stations in West Africa from 2015 to 2019, indicating the stations' varying performance of data acquisition.

which induces an extra delay on GNSS measurements. Tropospheric delay is a function of the total refractivity $(N)$, which depends on pressure ( $P$ (mbar or hpa)), temperature $((T(K))$, and relative humidity $(\mathrm{RH}(\%))$, or water vapour partial pressure (e (mbar or hpa)) along the signal transmission path as well as the location of the receiver antenna. The total delay computed in the zenith direction is called the zenith tropospheric/total delay (ZTD), which is the sum of the zenith hydrostatic delay (ZHD) and the zenith wet delay (ZWD). The ZHD accounts for about $90 \%$ of the ZTD and can easily be modelled or predicted to submillimetre accuracy by empirical prediction models using surface meteorological observations, whereas the ZWD accounts for the remaining $10 \%$ of the $\mathrm{ZTD}$, and in contrast to the $\mathrm{ZHD}$, it cannot be precisely modelled or predicted due to its large spatial and temporal variability $[40,41]$. The troposphere is characterized as being a nondispersive medium for radiofrequencies up to $15 \mathrm{GHz}$, and hence, its effect is independent of GNSS frequencies and therefore affects the carrier phase and code measurements equally [42].

Following $[2,5,43]$, the ZTD can be calculated by integration of the total refractivity $(N)$ along the signal transmission path, $s$, via the troposphere as

$$
\mathrm{ZTD}=10^{-6} \int_{s} N(s) \mathrm{d} s
$$

$N$ can be separated into hydrostatic $\left(N_{d}\right)$ and wet $\left(N_{w}\right)$ components caused by dry gases (mainly $\mathrm{N}_{2}$ and $\mathrm{O}_{2}$ ) and water vapour, respectively, as [42] follows:

$$
N=N_{d}+N_{w} \text {. }
$$

The refractivity $(N)$ can be related to the meteorological parameters $(P, T$, and $e)$ as [44] follows:

$$
N=\underbrace{\left[k_{1} \frac{P_{d}}{T}\right]}_{N_{d}}+\underbrace{\left[k_{2} \frac{e}{T}+k_{3} \frac{e}{T^{2}}\right]}_{N_{w}},
$$

where $P_{d}=P+e$ is the partial pressure of the dry gases (in hpa) and $k_{1}, k_{2}$, and $k_{3}$ are refractivity constants whose values according to [6] are given as $k_{1}=77.60 \pm 0.05 \mathrm{~K} / \mathrm{hpa}$, $k_{2}=70.40 \pm 2.2 \mathrm{~K} / \mathrm{hpa}$, and $k_{3}=373900 \pm 1200 \mathrm{~K}^{2} / \mathrm{hpa}$.

Equation (3) can further be rewritten with the assumption that the air in the troposphere behaves as an ideal gas, and equation (3) becomes $[37,45]$

$$
N=\left[k_{1} \frac{P}{T}\right]+\left[k_{2}^{\prime} \frac{e}{T}+k_{3} \frac{e}{T^{2}}\right]=N_{h}+N_{w}
$$

where $k_{2}^{\prime}=k_{2}-k_{1}$ for NWP models and $N$ can be computed as $[8,37,46-49]$ follows:

$$
N=k_{1} \frac{P-e}{T}+k_{2} \frac{e}{T}+k_{3} \frac{e}{T^{2}} .
$$

Here, $P$ and $T$ are based on pressure-level data and $e$ computed as

$$
e=q \times P / 0.622,
$$

where $q$ is the specific humidity (in $\mathrm{kg} / \mathrm{kg}$ or unitless).

Equation (1) can be expanded to

$$
\mathrm{ZTD}=\underbrace{10^{-6} \int_{h}^{\mathrm{TOA}} N_{d}(h) \mathrm{d} h}_{\text {ZHD }}+\underbrace{10^{-6} \int_{h}^{\mathrm{TOA}} N_{w}(h) \mathrm{d} h}_{\text {ZWD }},
$$

where $h$ is the height of the station or receiver antenna and TOA is the top of the atmosphere.

For NWP models, the final ZTD is computed as follows $[8,37,46-49]$ :

$$
\mathrm{ZTD}=\mathrm{ZHD}_{\text {top }}+\mathrm{ZTD}_{\text {level }} \text {, }
$$

where $\mathrm{ZHD}_{\text {top }}$ is the delay at the top-level computed using Saastamoinen model as follows [12]:

$$
\begin{aligned}
& \mathrm{ZHD}_{\text {top }}=0.002277 \cdot \frac{P_{\text {top }}}{1-0.00266 \cdot \cos (\varphi)-2.8 \times 10^{-7} h_{\text {top }}}, \\
& \mathrm{ZTD}_{\text {level }}=10^{-6} \int_{h}^{h_{\text {top }}} N \mathrm{~d} h=10^{-6} \sum_{i=1}^{\text {top }} N_{i} \Delta s_{i},
\end{aligned}
$$


where $P_{\text {top }}$ is the pressure at the top level (in hpa), $\varphi$ is the latitude of the station; $h_{\text {top }}$ is the top-level altitude (in meters); $N_{i}$ is the total refractivity at the $i$-th level, computed using Equation (5); top is the number of levels of the NWP model; and $\Delta s_{i}$ is the geometric distance (in meters) between the $i$-th and $(i+1)$-th layer of the NWP model given as follows [47]:

$$
\Delta s_{i}=Z_{i+1}-Z_{i},
$$

where $Z$ represents the height of the pressure level (in meters).

With an appropriate mapping function and using the satellite elevation angle $(\theta)$ as input, the ZTD can be resolved into the slant tropospheric delay (STD) as follows:

$$
\operatorname{STD}_{r}^{t}=\mathrm{ZHD} \times \mathrm{MF}_{h}(\theta)+\mathrm{ZWD} \times \mathrm{MF}_{w}(\theta) .
$$

For the PPP technique, ZTD is estimated using the GNSS observation equation of the ionosphere-free linear code and phase combinations and all needed ancillary information as follows [38, 48]:

$$
\begin{aligned}
\mathrm{STD}= & \mathrm{ZHD} \cdot \mathrm{MF}_{h}(\theta)+\mathrm{ZWD} \cdot \mathrm{MF}_{w}(\theta)+ \\
& \mathrm{MF}_{G} \cdot \cot (\theta) \cdot\left[G_{N} \cdot \cos (A)+G_{E} \cdot \sin (A)\right],
\end{aligned}
$$

and ZTD can finally be computed as

$$
\mathrm{ZTD}=\mathrm{STD} \cdot \frac{1}{\mathrm{MF}(\theta)},
$$

where $\mathrm{MF}_{h}$ and $\mathrm{MF}_{w}$ represent the hydrostatic and wet mapping functions, SHD and SWD are the slants hydrostatic and wet tropospheric delays, $A$ is the azimuth angle, $\mathrm{MF}_{G}$ is the gradient mapping function, and $G_{N}$ and $G_{E}$ represent the horizontal north and east gradients.

The ZWD can then be converted to PWV for meteorological applications using a conversion factor pie $(\Pi)$ as follows [6]:

$$
\mathrm{PWV}=\Pi * \mathrm{ZWD} .
$$

$\Pi$ is dimensionless and can be determined from [50]:

$$
\Pi=\frac{10^{6}}{\left(\left(k_{3} / T_{m}\right)+k_{2}^{\prime}\right) \rho_{w} R_{w}},
$$

where $R_{w}$ is the specific gas constant for water vapour (461.5 $\left.\mathrm{JKg}^{-1} \mathrm{~K}^{-1}\right), \rho_{w}$ is the density of water $\left(998 \mathrm{kgm}^{-3}\right), T_{m}$ is the weighted mean temperature in kelvin $(\mathrm{K})$, and $k_{2}^{\prime}$ is refractivity constant $(16.52 \mathrm{~K} / \mathrm{hpa})$. Tm can be obtained from global or regional Tm models such as follows [5]:

$$
T_{m}=0.72 \cdot T_{s}+70.2 \text {. }
$$

\section{Materials and Methods}

3.1. Study Area. This study was conducted using five IGS stations located in five West African countries, namely, Nigeria (CGGN), Benin (BJCO), Cote d'Ivoire (YKRO), Senegal (DAKR), and Cape Verde (CPVG). The West
African region lies between latitudes $0^{\circ} \mathrm{N}$ and $25^{\circ} \mathrm{N}$ and longitudes $20^{\circ} \mathrm{W}$ and $20^{\circ} \mathrm{E}$. The details of the stations and their visual locations are shown in Table 1 and Figure 2, respectively.

3.2. ZTD Datasets. The study used the daily sitewise operational VMF3 ("VMF3_O") ZTD product for IGS stations and the IGS final ZTD products for a period of five years from 2015 to 2019. The following subsections summarize the datasets used in this study.

3.2.1. VMF3-ZTD Data. The Vienna Mapping Function (VMF) service (https://vmf.geo.tuwien.ac.at/) provides both gridded and sitewise ray-traced VMF1 and VMF3 tropospheric products as open-access data for global and more than 500 IGS stations users. They are generated based on raytraced delays at $3^{\circ}$ elevation using NWP model data spanning 2001 to 2010 from the European Centre for Medium-Range Weather Forecasts (ECMWF) ERA-40 and ERA-Interim reanalysis data, respectively [38]. They are provided every 6 hours daily at four epochs $(00,06,12$, and $18 \mathrm{UT})$ and at $23 \mathrm{~h}$ UT the next day [51]. VMF3 is the successor of VMF1 realized on both $1^{\circ} \times 1^{\circ}$ and $5^{\circ} \times 5^{\circ}$ global grids [17]. The sitewise tropospheric delay products provided for the IGS stations include ZHD, ZWD, meteorological parameters like pressure $(P)$, temperature $(T)$, and water vapour partial pressure (e), and mapping function coefficients for both hydrostatic (ah) and wet (aw) components. The ZTD is obtained by adding ZHD and ZWD. The VMF3-ZTD data are available at https://vmf.geo.tuwien.ac.at/trop_products/ GNSS/VMF3/.

3.2.2. IGS-ZTD Data. The IGS also publishes daily final ZTD products based on PPP techniques combined with IGS precise final orbit and clock solutions for all IGS groundbased tracking stations with an accuracy of about $4 \mathrm{~mm}$. The zenith delays are computed at an interval of 5 minutes from the IGS stations and are released with 4-week latency [18]. The IGS-ZTD products are mostly used as a standard reference to validate other models or products owing to its high-accurate ZTD estimate. The IGS-ZTD data are available at ftp://cddis.gsfc.nasa.gov/pub/gps/products/ trop_new.

\subsection{Methodology}

3.3.1. ZTD Extraction. The downloaded daily datasets were extracted into Microsoft Excel for easy exploration and analysis. The extractions were done using coded scripts or m-files, "read_vmfGNSS.m," and "ReadIGSTrop.m" written in Matlab programming language for this study. For the VMF3-ZTD data, the "read_vmfGNSS. $m$ " $\mathrm{m}$-file was used to extract all the needed parameters in the data file. The parameters extracted were ZHD and ZWD for each epoch $(00$, 06,12 , and $18 \mathrm{UT}$ ) daily and the first epoch (00 h UT) of the next day to obtain complete data for 24 hours or $23 \mathrm{~h} \mathrm{UT}$. No interpolation or extrapolation was performed since the 
TABLE 1: IGS stations in West Africa selected for this study.

\begin{tabular}{|c|c|c|c|c|c|c|}
\hline Site & City & Country & Latitude & Longitude & Ellip. height $(\mathrm{m})$ & Period of data \\
\hline $\mathrm{BJCO}$ & Cotonou & Benin & $6.3847^{\circ} \mathrm{N}$ & $02.4500^{\circ} \mathrm{E}$ & 30.700 & 2015-2019 \\
\hline YKRO & Yamoussoukro & Cote d'Ivorie & $6.8706^{\circ} \mathrm{N}$ & $05.2401^{\circ} \mathrm{W}$ & 270.000 & 2015-2019 \\
\hline CGGN & Toro & Nigeria & $10.1231^{\circ} \mathrm{N}$ & $09.1183^{\circ} \mathrm{E}$ & 916.695 & $2015-2016$ \\
\hline DAKR & Dakar & Senegal & $14.7212^{\circ} \mathrm{N}$ & $17.4395^{\circ} \mathrm{W}$ & 51.000 & 2015-2019 \\
\hline CPVG & Espargos & Cape Verde & $16.7321^{\circ} \mathrm{N}$ & $22.9349^{\circ} \mathrm{W}$ & 94.089 & 2015-2019 \\
\hline
\end{tabular}

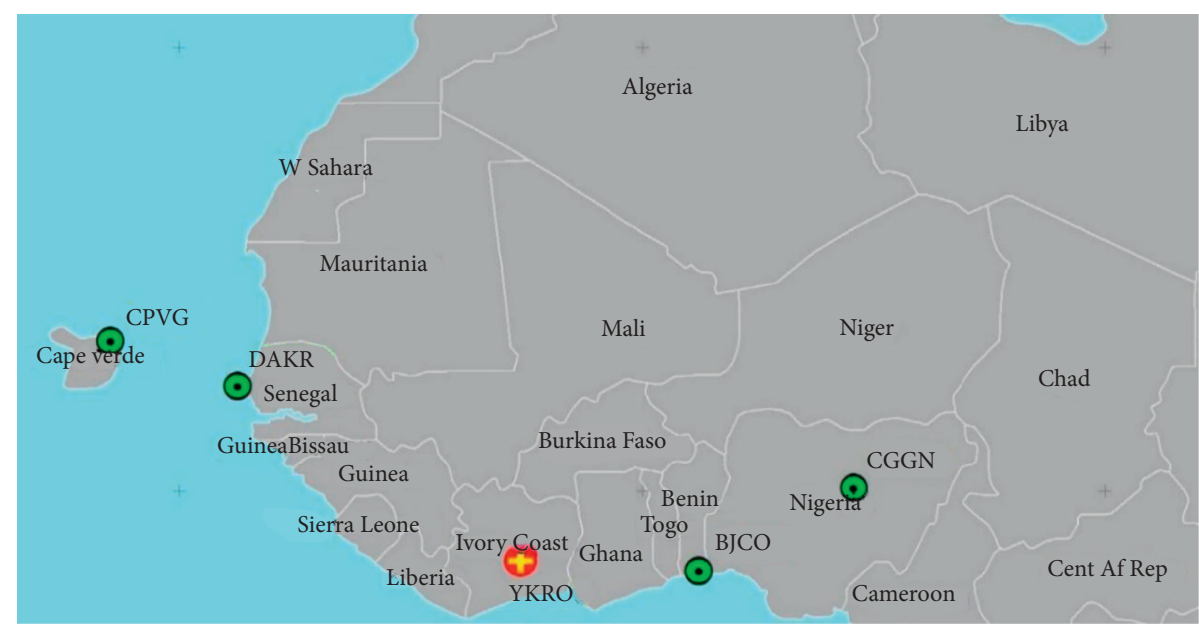

FIgURE 2: Map of West Africa showing the locations of the five IGS stations used.

sitewise parameters are computed at station height, and therefore, no extrapolation was required to transfer from grid height to station height. The daily mean $\mathrm{ZHD}(\overline{\mathrm{ZHD}})$ and mean ZWD ( $\overline{Z W D})$ were found by summing all the daily epochs $(00,06,12$, and $18 \mathrm{UT})$ and the first epoch $(00 \mathrm{~h}$ UT) the next day and dividing by 5 to obtain the complete daily (24 hours) average datasets as follows:

$$
\begin{aligned}
\overline{\mathrm{ZHD}} & =\frac{\mathrm{ZHD}_{00}+\mathrm{ZHD}_{06}+\mathrm{ZHD}_{12}+\mathrm{ZHD}_{18}+\mathrm{ZHD}_{00 \text { nextday }}}{5}, \\
\overline{\mathrm{ZWD}} & =\frac{\mathrm{ZWD}_{00}+\mathrm{ZWD}_{06}+\mathrm{ZWD}_{12}+\mathrm{ZWD}_{18}+\mathrm{ZWD}_{00 \text { nextday }}}{5} .
\end{aligned}
$$

The mean daily ZTD $\left.\left(\overline{\mathrm{ZTD}}_{\mathrm{vmf} 3}\right)\right)$ is obtained as

$$
\overline{\mathrm{ZTD}}_{\mathrm{vmf} 3}=\overline{\mathrm{ZHD}}+\overline{\mathrm{ZWD}} \text {. }
$$

Likewise, the IGS-ZTD data were also extracted using the "ReadIGSTrop.m" $m$-file. Since the IGS-ZTD is computed at an interval of 5 minutes (temporal resolution) for each day, the mean ZTD $\left(\overline{Z T D}_{\text {igs }}\right)$ was also calculated for the entire day $(24 \mathrm{~h})$ for each file, by summing all the ZTDs at each epoch and dividing by the total number of epochs in the file, presented as

$$
\overline{\mathrm{ZTD}}_{\mathrm{igs}}=\sum_{i=1}^{n} \frac{\mathrm{ZTD}_{e}}{n},
$$

where $n=288$ is the total number of epochs and $\mathrm{ZTD}_{e}$ is the ZTD at each epoch.
For each IGS station, the two datasets (VMF3-ZTD and IGS-ZTD) were compared and the corresponding days of data availability were extracted and sorted for analysis. Figure 3 provides a summary flow of the methodology. The total number of days of data available for each station in a given year within the study period is also shown in Figure 1.

3.3.2. Performance Evaluation. To evaluate the performance of the VMF3-ZTD product with respect to the IGS final ZTD product over West Africa, the IGS final ZTD data at the five West African IGS stations for the entire five-year period were taken as references for comparison. To conduct an indepth and insightful evaluation and comparison, several statistic evaluation indicators are necessary. Hence, the following selected number of statistical indicators, mean bias $(\mathrm{MB})$, mean absolute error (MAE), root mean square error (RMSE), refined index of agreement $\left(\mathrm{IA}_{\mathrm{r}}\right)$, Nash-Sutcliffe coefficient of efficiency (NSE), Pearson correlation coefficient $(r)$, coefficient of determination $\left(r^{2}\right)$, and the fraction of predictions within a factor of two (FAC2) [52-55] are computed. Equations for the computation of these indicators are provided as follows:

$$
\begin{aligned}
\mathrm{MB} & =\frac{1}{N} \sum_{i=1}^{N}\left(M_{i}-O_{i}\right), \\
\mathrm{MAE} & =\frac{1}{N} \sum_{i=1}^{N}\left|M_{i}-O_{i}\right|,
\end{aligned}
$$




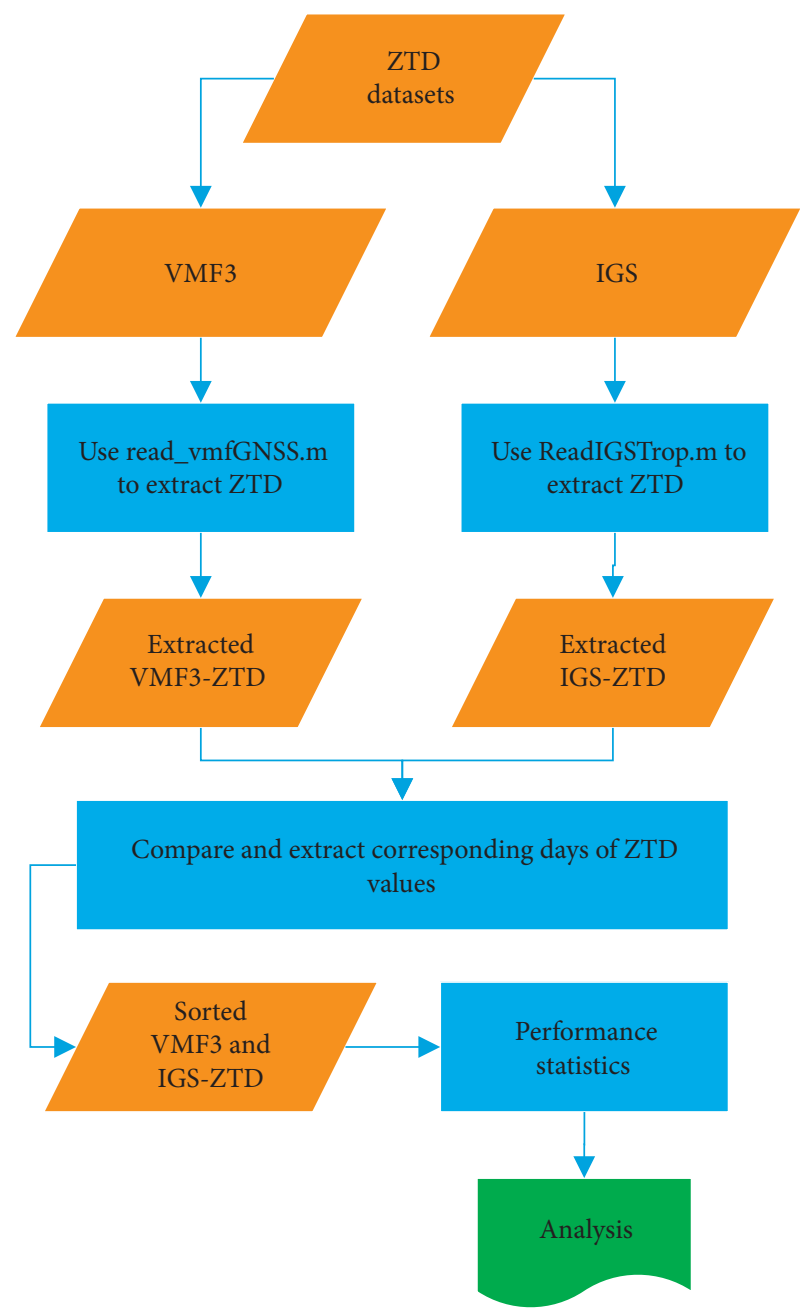

FIgURE 3: A summary flow of the methodology.

$$
\begin{aligned}
\mathrm{RMSE} & =\sqrt{\frac{1}{N} \sum_{i=1}^{N}\left(M_{i}-O_{i}\right)^{2}}, \\
r & =\frac{\sum_{i=1}^{N}\left(M_{i}-\bar{M}\right) \times\left(O_{i}-\bar{O}\right)}{\left[\sqrt{\sum_{i=1}^{N}\left(M_{i}-\bar{M}\right)^{2}}\right]\left[\sqrt{\sum_{i=1}^{N}\left(O_{i}-\bar{O}\right)^{2}}\right]}
\end{aligned}
$$$$
\mathrm{NSE}=1-\left[\frac{\sum_{i=1}^{N}\left(O_{i}-M_{i}\right)^{2}}{\sum_{i=1}^{N}\left(O_{i}-\bar{O}\right)^{2}}\right],
$$$$
\mathrm{IA}_{r}= \begin{cases}1-\frac{\sum_{i=1}^{N}\left|M_{i}-O_{i}\right|}{2 \sum_{i=1}^{N}\left|O_{i}-\bar{O}\right|}, & \text { when } \sum_{i=1}^{N}\left|M_{i}-O_{i}\right| \leq 2 \sum_{i=1}^{N}\left|O_{i}-\bar{O}\right|, \\ \frac{2 \sum_{i=1}\left|O_{i}-\bar{O}\right|}{\sum_{i=1}^{N}\left|M_{i}-O_{i}\right|}-1, & \text { when } \sum_{i=1}^{N}\left|M_{i}-O_{i}\right|>2 \sum_{i=1}^{N}\left|O_{i}-\bar{O}\right|,\end{cases}
$$

FAC $2=0.5 \leq \frac{M_{i}}{O_{i}} \leq 2.0$, where $M_{i}$ and $O_{i}$ represent the $i^{\text {th }}$ modelled (VMF3) and observed (IGS) ZTDs, respectively, and $\bar{M}$ and $\bar{O}$ their respective means. $N$ is the total number of observations.

An interesting perspective on model performance is provided by the performance measures/metrics indicated above. They can be categorised into the following $[53,56]$ :

(i) Measures of difference or error index (MB, MAE, and RMSE)

(ii) Measures of correlation $\left(r\right.$ and $\left.r^{2}\right)$

(iii) Measures of efficiency (NSE, IA $A_{r}$ and FAC2). These measures or indicators are less common in the GNSS field.

The MB provides an indication of whether the mean VMF3-ZTD predictions are under (value when negative) or over (value when positive) estimated. The MAE also indicates the magnitude of the mean error regardless of whether it is over or underestimated, while the RMSE provides an overall measure of how close the VMF3-ZTD values are to the IGS values. The smaller the MB, MAE, and RMSE values, the better the model (VMF3) predictions. The MB, MAE, and RMSE are the most widely used forecast evaluation metrics in the field of GNSS.

$r$ provides a measure of collinearity between the VMF3 and IGS datasets. It is scaled such that it ranges from -1 to $+1 . r=0$ indicates that there is no linear relationship between the two datasets (VMF3 and IGS), and the relationship intensifies as the absolute value of $r$ increases, eventually approaching a straight line as the coefficient approaches -1 or +1 . The $r$ value closer to 1 implies a high degree of association between the IGS and VMF3 datasets (i.e., good model performance). $r^{2}$ ( $r$-squared) is the squared value of $r$ and indicates how much of the total variation in the IGS data is explained by the VMF3-ZTD prediction. $r^{2}$ value is in the range of 0 and 1 or $0 \%$ and $100 \%$.

NSE determines the relative magnitude of the residual variance compared to the variance of the observed data [55]. As reported in [57], NSE provides a more direct measure of the agreement between the observed (IGS) and predicted (VMF3) data than $r^{2}$. Legates and Mccabe [58] finally stressed that NSE is a necessary quality for any metric of model evaluation. A value of NSE closer to 1 indicates that the model (VMF3) can reproduce satisfactorily the observed (IGS) data, with NSE $=1.0$, indicating a perfect match of the model (VMF3) predictions to the observed (IGS) data. $\mathrm{IA}_{\mathrm{r}}$ also measures the degree to which a model prediction is error-free. It varies between -1 and $+1\left(-1 \leq \mathrm{IA}_{\mathrm{r}} \leq 1\right)$ with values approaching +1 representing better model performance [52]. FAC2 measures the fraction or percentage of the VMF3 model's predictions within a factor of two or that satisfies the condition in equation $(26)[54,59]$. FAC2 has been described as a robust performance measure since it is not overly affected by outliers [59]. FAC2 value closer to 1.0 indicates a closer match between the modelled (VMF3) and observed (IGS) values and therefore indicates better model performance. A perfect model has a $\mathrm{FAC} 2=1$.

To further investigate the performance of the VMF3ZTD model, a multiple comparison test (MCT) with the 
"Scheffe" method $[60,61]$ was performed to test whether the difference in the mean values of the VMF3-ZTD product and the IGS-ZTD product is significant at $5 \%$ significant level using Matlab multicompare function. The null and alternate hypothesis ( $\mathrm{H} 0$ and $\mathrm{Ha}$ ) tests are stated as follows:

H0: the difference between the means is equal to 0 .

Ha: the difference between the means is different from 0 .

Matlab MCT provides an interactive graph with each group mean represented by a symbol (small circle) and a comparison interval or bar represented by a line extending out from the symbol, as shown in Figure 4. Mean of two groups (e.g., A and B) is significantly different if their intervals are disjoint and significantly indifferent if their intervals overlap or intersect. For a selected group (e.g., B), the comparison bar is highlighted blue and all other groups that are significantly different are highlighted red (e.g., A and E). The bars for the groups that are not significantly different are highlighted in grey (e.g., C and D), as shown in Figure 4. It is important to note that Figure 4 is a sample graph used to explain the MCT and not a graph created in this study.

\section{Results and Discussion}

The focus of this paper is to compare the performance of the VMF3-ZTD product with the IGS final ZTD product in terms of precision and accuracy using IGS-ZTD data from five IGS stations in West Africa as benchmarks over a five-year period. The results of the various statistical computations MB, MAE, RMSE, IA $\mathrm{A}_{\mathrm{r}}$ NSE, $r, r^{2}$, and FAC2 for each IGS station are summarised in Table 2. As already indicated, to evaluate the performance of the VMF3-ZTD model predictions, it is important to measure how well its predictions match the IGSZTD values. The MB, MAE, and RMSE help to quantify how close the VMF3-ZTD values are to the IGS-ZTD values. The smaller the MB, MAE, and RMSE values (closer to zero) are, the closer the VMF3-ZTD predictions are to the IGS-ZTD values, and the better the predictions. It can be seen from Table 2 that all the stations have smaller MB, MAE, and RMSE values, demonstrating good agreement between the VMF3ZTD and IGS-ZTD values and hence better performance of the VMF3-ZTD predictions.

Furthermore, to measure the degree of relationship between the VMF3-ZTD and IGS-ZTD values and to quantify the proportion of variance in the IGS-ZTD values that is accounted for by the VMF3-ZTD values, $r$ and $r^{2}$, respectively, became useful tools. As discussed above, an $r$ value closer to 1 signifies a high degree of relationship between the IGS and VMF3 predictions. Also, the larger the $r^{2}$ value, the greater the explanatory power. The results in Table 2 clearly show that all the IGS stations have $r$ values close to 1, connoting a stronger relationship between the two datasets based on the criteria in [62]. It can also be observed that the IGS stations have $r^{2}$ values close to 1 , indicating that a greater portion $(94.5 \%$ $99.6 \%$ ) of the total variation in the IGS-ZTD data has been explained by the VMF3-ZTD data. In line with [57], a model's prediction (VMF3) is considered ideal or perfect if $r^{2} \geq 0.97$ or $r^{2} \geq 0.93$ and acceptable if $r^{2} \geq 0.90$ or $r^{2} \geq 0.77$. This implies

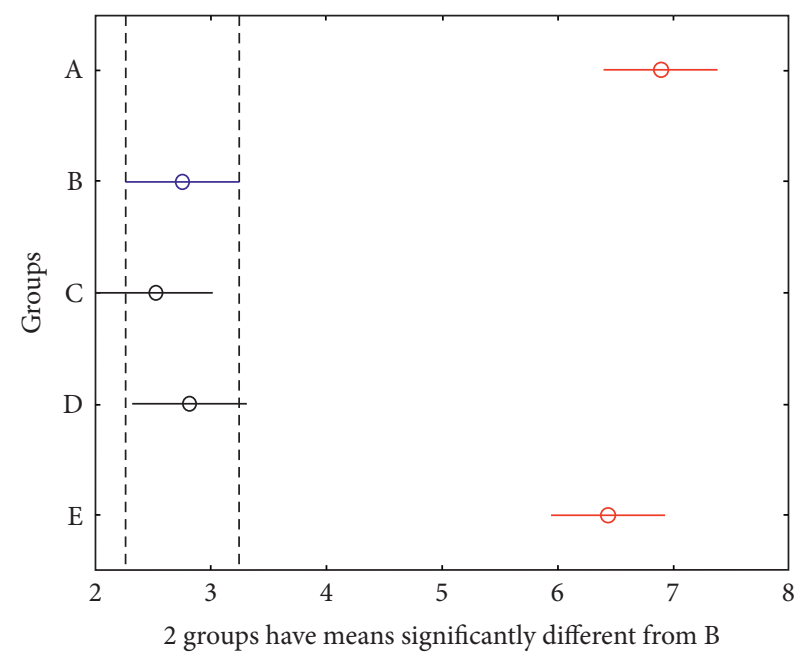

FIGURE 4: Sample graph of multiple comparisons of group means.

that the VMF3-ZTD model predictions match well with the IGS-ZTD predictions. IGS station CGGN had the highest $r^{2}$ of 0.996 (99.6\% explained), and YKRO had the lowest $r^{2}$ of 0.945 (94.5\% explained). As evidenced from the scatterplots in Figure 5 , it can be seen very clearly that the data points are closer to the regression lines, which according to [63], when a model (VMF3) accounts for more of the variance in the observed values (IGS), the data points are closer to the regression line. Therefore, this clearly shows the exceptional predictive performance of the VMF3-ZTD model.

Additionally, to measure the efficiency of the VMF3ZTD model predictions as a means of assessing its predictive performance, NSE, $\mathrm{IA}_{\mathrm{r}}$, and FAC2 were utilised. According to the NSE, $\mathrm{IA}_{\mathrm{r}}$, and FAC2 values in Table 2, the VMF3-ZTD model showed a phenomenal performance in the prediction of ZTD in the study area. Table 2 shows NSE values closer to 1 in all the stations. IGS station CGGN recorded the highest NSE of 0.995 and YKRO the lowest NSE of 0.907. In accordance with [57, 64] model classification criteria, a model is considered perfect for prediction if NSE $\geq 0.93$, very good if NSE $\geq 0.80$, and satisfactory if NSE $\geq 0.60$. Consistent with these model performance criteria, it is clear that the VMF3 model predictions match excellently well with the IGS predictions. Moreover, $\mathrm{IA}_{\mathrm{r}}$ values approaching +1 represent better model performance [52] as prior indicated. It is evident from the results in Table 2 that all the stations have $\mathrm{IA}_{\mathrm{r}}$ values closer to 1 , indicating a better model performance. Likewise, FAC2 value closer to 1.0 also indicates a closer match between modelled (VMF3) and observed (IGS) values and therefore shows better model performance. From Table 2, the VMF3ZTD model again demonstrated excellent performance with $100 \%$ of its predictions at all the stations within the factor of two (FAC2) of the IGS-ZTD data.

Figures 6 and 7 show the daily and yearly variations in the IGS-ZTD and VMF3-ZTD values at all the IGS stations, allowing a quantitative comparison between VMF3 model ZTDs and that of the IGS-ZTDs at each IGS station. Figures 6 and 7 clearly show a comparable match of performance between the two datasets. 
TABLe 2: Statistical evaluation parameters for each IGS station in the study.

\begin{tabular}{|c|c|c|c|c|c|c|c|c|c|}
\hline Site & $N$ & $\mathrm{MB}(\mathrm{M})$ & $\operatorname{MAE}(\mathrm{M})$ & RMSE (M) & $r(-)$ & $r^{2}(-)$ & NSE (-) & $\operatorname{IAr}(-)$ & FAC2 (-) \\
\hline $\mathrm{BJCO}$ & 1194 & 0.0008 & 0.0082 & 0.0105 & 0.9817 & 0.9638 & 0.9612 & 0.9905 & 1.00 \\
\hline YKRO & 1180 & 0.0112 & 0.0133 & 0.0170 & 0.9722 & 0.9451 & 0.9068 & 0.9750 & 1.00 \\
\hline CGGN & 174 & 0.0025 & 0.0084 & 0.0106 & 0.9978 & 0.9957 & 0.9954 & 0.9988 & 1.00 \\
\hline DAKR & 1245 & 0.0057 & 0.0081 & 0.0102 & 0.9948 & 0.9895 & 0.9849 & 0.9962 & 1.00 \\
\hline CPVG & 915 & -0.0011 & 0.0057 & 0.0072 & 0.9941 & 0.9883 & 0.9877 & 0.9970 & 1.00 \\
\hline Mean & & 0.00382 & 0.00874 & 0.0111 & 0.98812 & 0.97648 & 0.9672 & 0.9915 & 1.00 \\
\hline
\end{tabular}

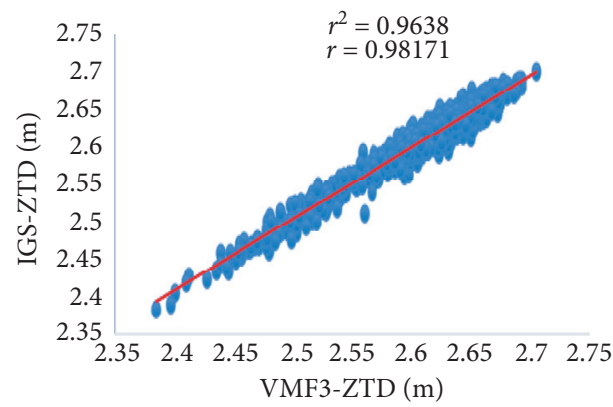

(a)

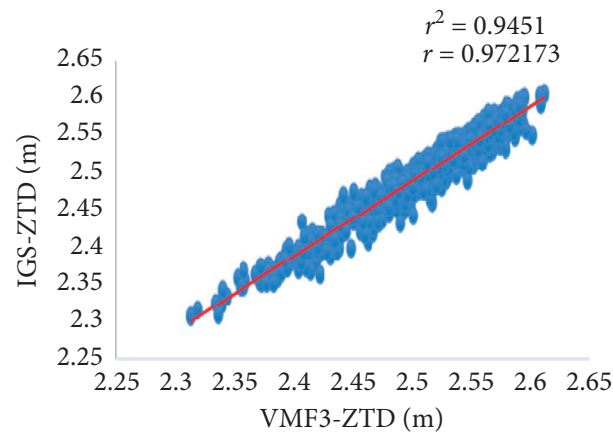

(c)

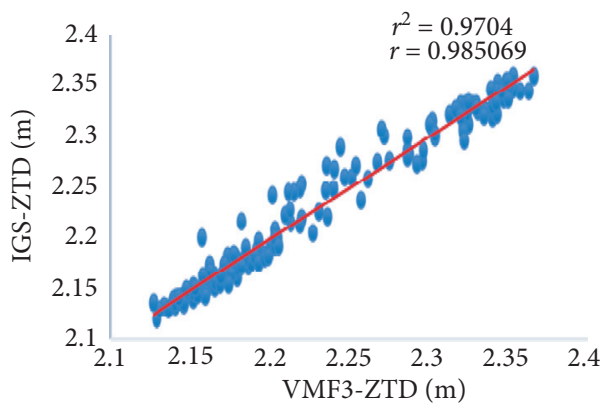

(b)

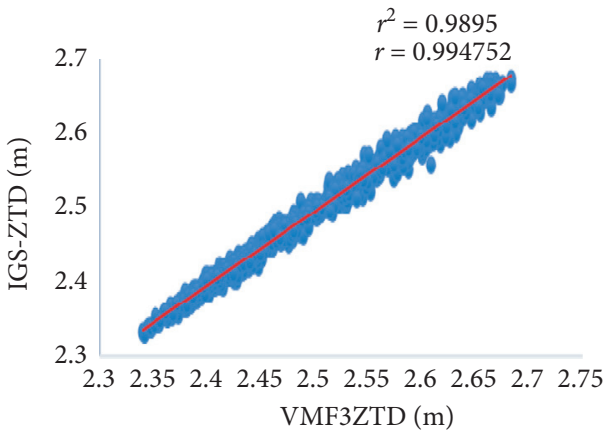

(d)

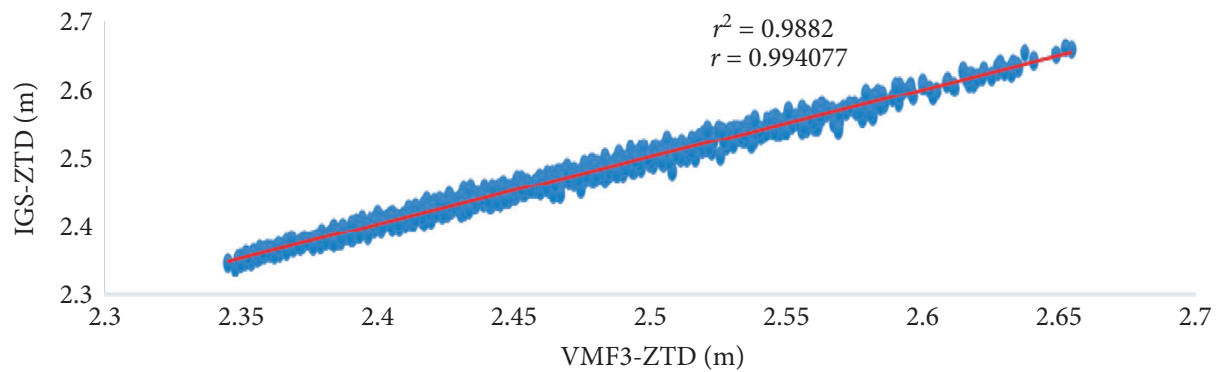

(e)

FIGURE 5: Scatterplots showing the strength of association between the IGS-ZTD and VMF3-ZTD at each IGS station. $r$ and $r^{2}$ are the correlation coefficient and coefficient of determination, respectively. The red lines represent the regression lines. (a) BJCO; (b) YKRO; (c) CGGN; (d) DAKR; (e) CPVG.

To further evaluate the degree of correspondence between the VMF3-ZTD and IGS-ZTD products, Taylor's diagram was employed and plotted for the five IGS stations under study, as shown in Figure 8. Taylor diagrams [65] graphically display the summary of how closely a model prediction (VMF3) matches the observations (IGS). The similarity between the two models is computed in terms of the correlation coefficients, centred RMSE, and standard deviation. From the various graphs in Figure 8, the position of each coloured symbol (red, blue, yellow, green, and black) quantifies how closely the VMF3-ZTD predictions at each station match the IGS-ZTD values. The black dashed arc in the diagram represents the observed (IGS) standard deviation at the point marked by "observed" on the $x$-axis. 


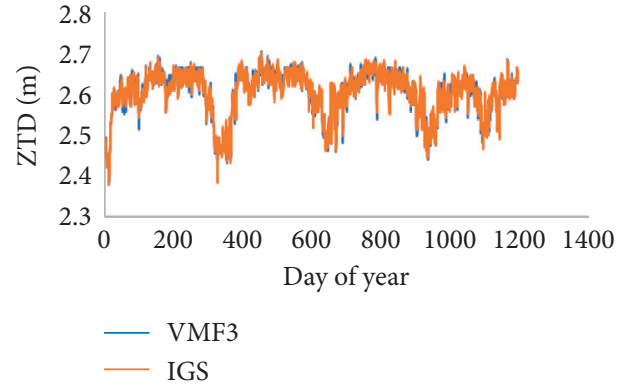

(a)

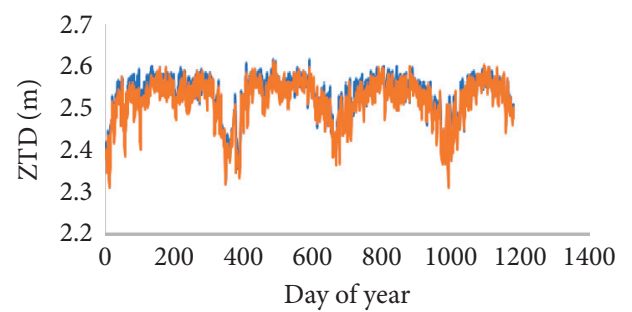

- VMF3

- IGS

(c)

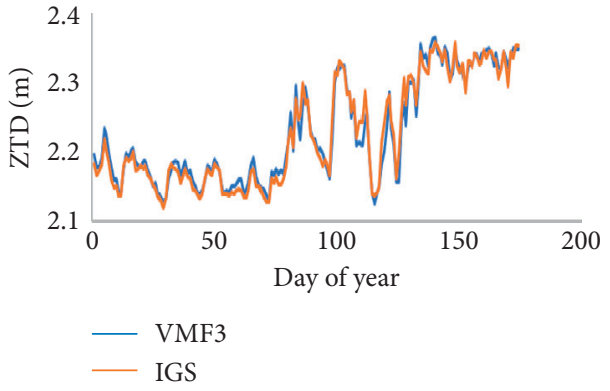

(b)

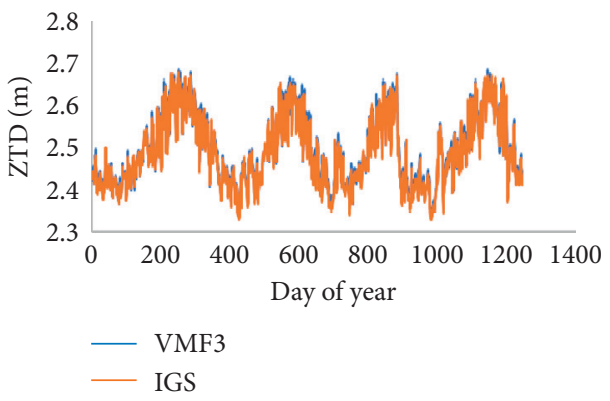

(d)

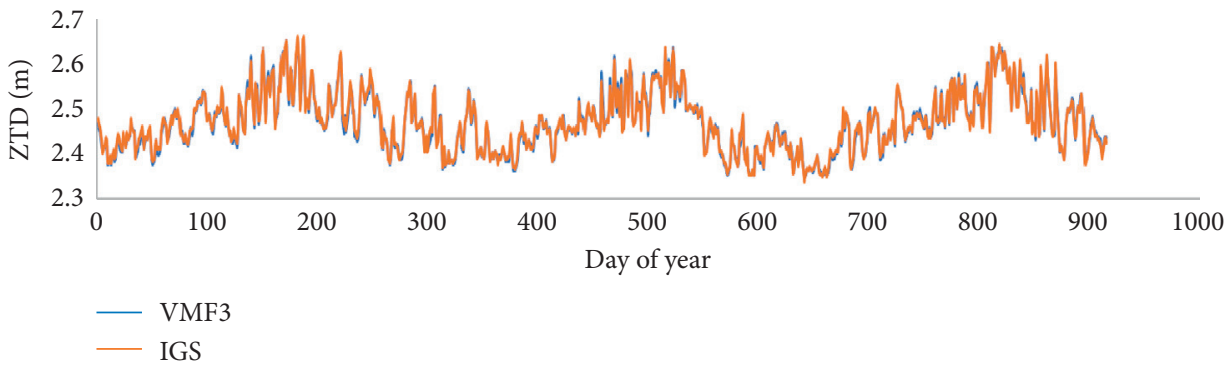

(e)

FIGURE 6: Daily variation in IGS and VMF3 ZTD values at each IGS station for the study period: (a) BJCO; (b) YKRO; (c) CGGN; (d) DAKR; (e) CPVG.

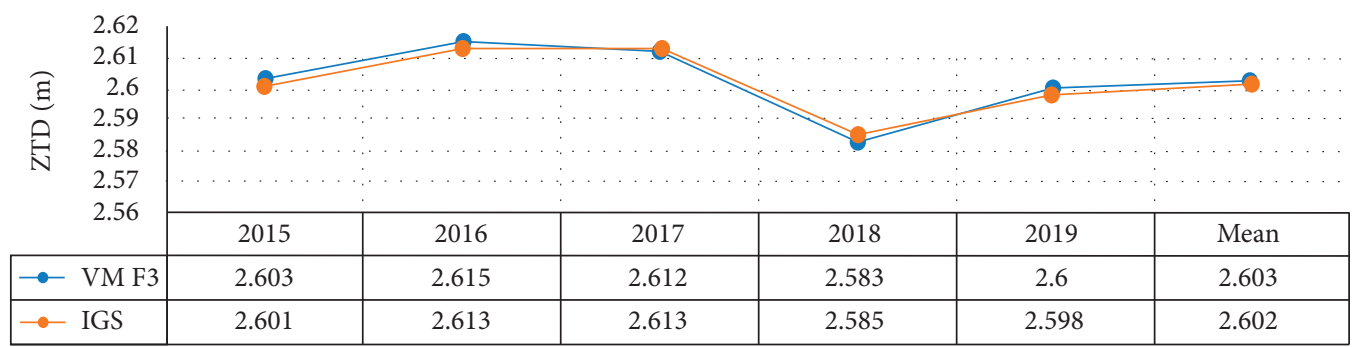

(a)

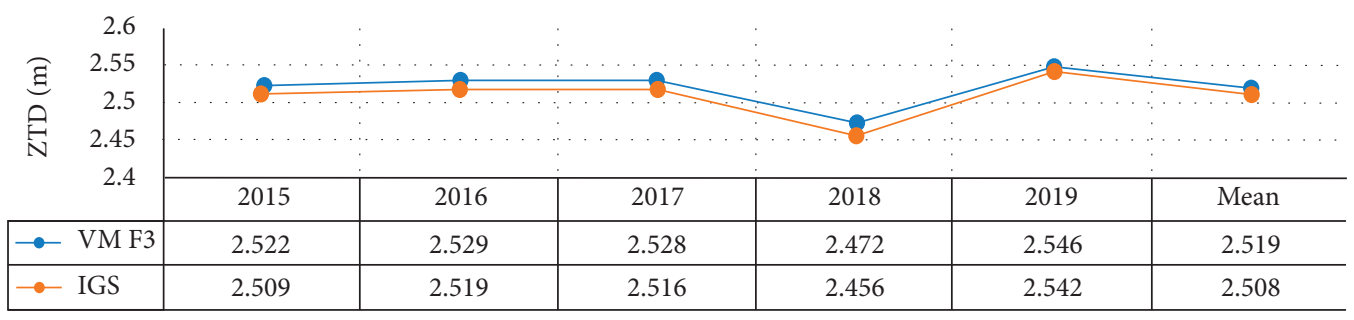

(b)

Figure 7: Continued. 


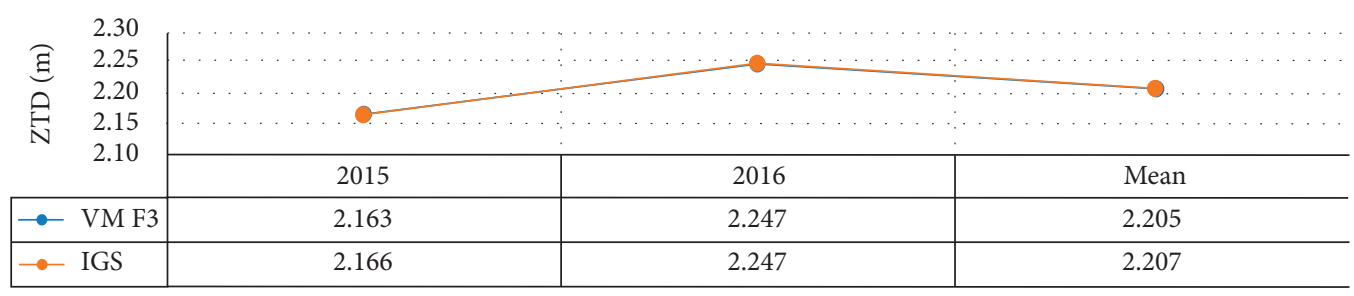

(c)

\begin{tabular}{|c|c|c|c|c|c|c|}
\hline $\begin{array}{ll} & 2.55 \\
\overparen{\Xi} & 2.50 \\
\stackrel{\Xi}{\mathrm{N}} & 2.45 \\
& 2.40\end{array}$ & & $=$ & & . & $\Longrightarrow$ & $\stackrel{.}{\circ}$ \\
\hline 2.35 & 2015 & 2016 & 2017 & 2018 & 2019 & Mean \\
\hline$\bullet-\mathrm{VM} \mathrm{F} 3$ & 2.426 & 2.507 & 2.489 & 2.481 & 2.497 & 2.480 \\
\hline$\rightarrow$ IGS & 2.421 & 2.503 & 2.483 & 2.473 & 2.492 & 2.474 \\
\hline
\end{tabular}

(d)

\begin{tabular}{|c|c|c|c|c|c|c|c|}
\hline \multirow{2}{*}{$\begin{array}{l}\text { छ્ } \\
\stackrel{\ominus}{\mathrm{N}}\end{array}$} & \multirow[t]{2}{*}{$\begin{array}{l}2.50 \\
2.48 \\
2.46 \\
2.44 \\
2.42\end{array}$} & \multicolumn{6}{|c|}{ (1) } \\
\hline & & 2015 & 2016 & 2017 & 2018 & 2019 & Mean \\
\hline$\rightarrow$ & VM F3 & 2.466 & 2.488 & 2.451 & 2.461 & 2.466 & 2.466 \\
\hline$\rightarrow$ & IGS & 2.467 & 2.491 & 2.452 & 2.461 & 2.466 & 2.467 \\
\hline
\end{tabular}

(e)

FIGURE 7: Yearly and overall mean variation in IGS-ZTD and VMF3-ZTD at each IGS station in West Africa. (a) BJCO; (b) YKRO; (c) CGGN; (d) DAKR; (e) CPVG.

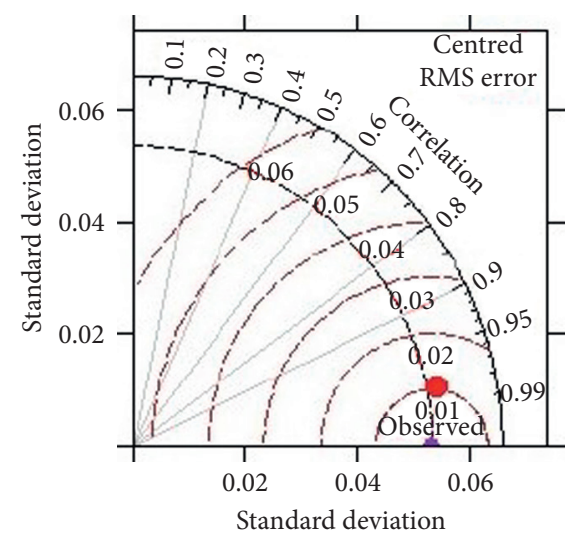

(a)

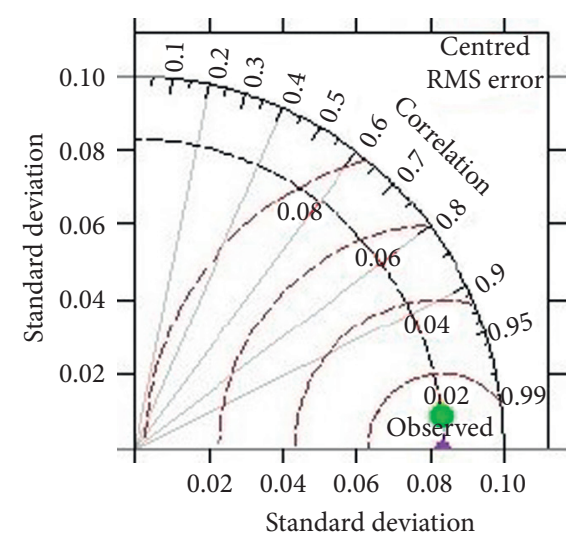

(d)

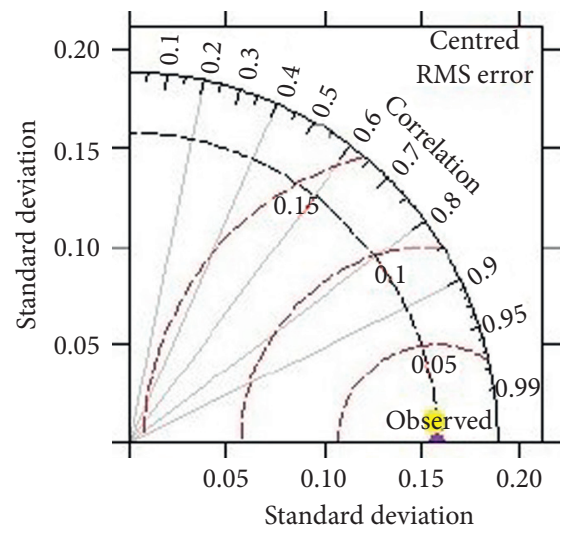

(b)

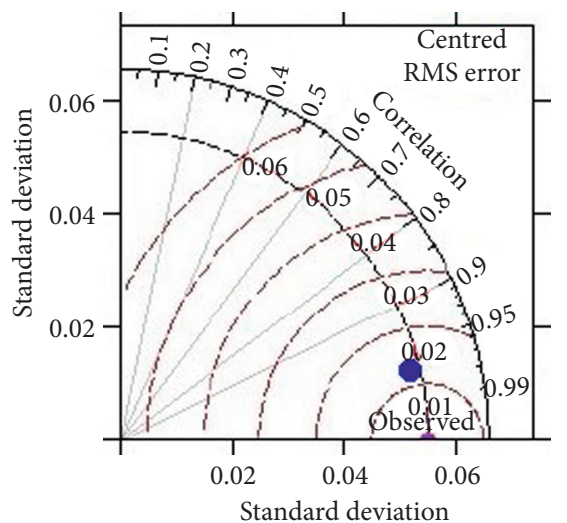

(c)

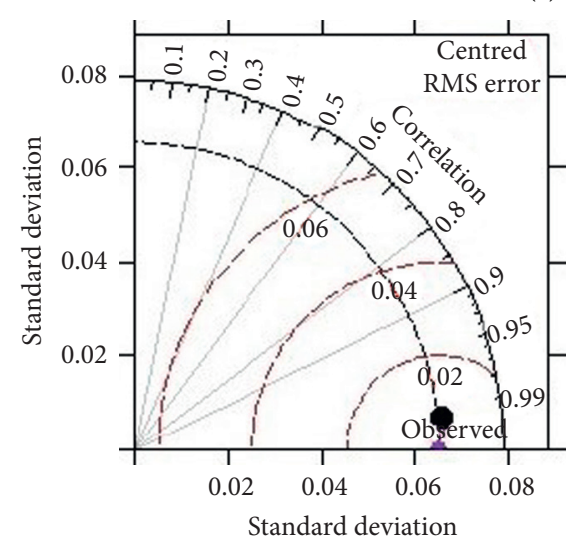

(e)

FIGURE 8: Taylor diagrams describing the correspondence between the IGS-ZTD and VMF3-ZTD values over West African IGS stations. The solid dots quantify how closely the VMF3-ZTD predictions at each station match the IGS-ZTD values: (a) BJCO; (b) YKRO; (c) CGGN; (d) DAKR; (e) CPVG. 


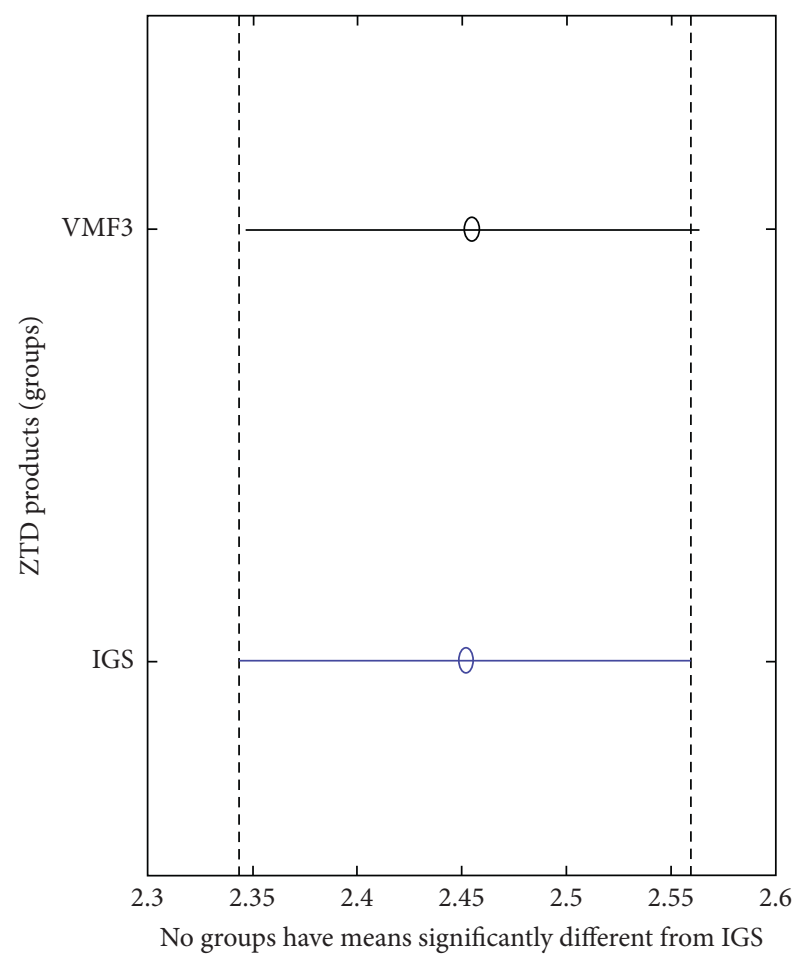

FIGURE 9: Multiple comparison of group (IGS and VMF3) means. The small circle symbols represent the group mean, while the bars (horizontal lines) represent the comparison interval.

Predictions that match well with the observed values will lie nearest or exactly on the black arc or the "observed" marked point having high correlation and low RMSEs. The red contours indicate the centred RMSE between the IGS and VMF3-ZTD datasets, which is proportional to the distance to the "observed" marked point on the $x$-axis. From Figure 8 , it can be seen that the VMF3-ZTD values at all the stations agree best with the IGS-ZTD data, with IGS station CGGN having the best match followed by DAKR and CPVG and then BJCO and YKRO.

Once more, the result of the multiple comparison test (MCT) is shown in Figure 9. As already indicated, the MCT was performed to test whether the difference in the mean values of the VMF3-ZTD product and the IGS-ZTD product is significant at 5\% significant level. It can be seen in Figure 9 that the mean of group 2 (IGS), which is shown in blue, is not significantly different from group 1 (VMF3), which is shown in grey, at $95 \%$ confidence level in the study area.

Finally, Table 2 also provides the overall average MB: $0.38 \mathrm{~cm}$, MAE: $0.87 \mathrm{~cm}$, RMSE: $1.11 \mathrm{~cm}, r: 0.988, r^{2}: 0.976$, NSE: 0.967, IA $\mathrm{r}$ : 0.992, and FAC2: 1.00 (100\%). It is evidently clear that the VMF3-ZTD model prediction provides such performance statistics, which demonstrates its excellent prediction performance.

\section{Conclusions}

The ability to precisely and accurately model and predict tropospheric delays has considerable implications on GNSS positioning and meteorological applications. Large data gaps resulting from inadequate and inconsistency data streaming from the West African IGS stations obstruct daily continuous ZTD estimates by the IGS centre, thereby degrading the quality of the ZTD. Consequently, because of the large data gaps, the provision of continuous daily time-series ZTD data needed to infer PWV for meteorological applications, climate monitoring, and atmospheric research in this region is mired. The need to investigate alternative data sources to address this issue is therefore very imperative. The performance of the sitewise VMF3-ZTD product was investigated in this study as a means of evaluating its suitability for use to improve continuous daily time-series ZTD data and also as a substitute in case the IGS-ZTD data at the IGS stations are unavailable. The evaluation was conducted by comparing the VMF3-ZTD product with the IGS-ZTD product using five selected IGS tracking stations across five West African countries over a five-year period (2015-2019). Eight distinct statistical performance measures, MB, MAE, RMSE, $r, r^{2}$, $\mathrm{IA}_{\mathrm{r}}, \mathrm{NSE}$, and FAC2, nonparametric post hoc or MCT, and graphical representations such as Taylor's diagrams, scatterplots, and time variation plots were utilised to determine the degree of agreement between the IGS and VMF3 tropospheric delay datasets. The results of the analysis showed that the VMF3 tropospheric product performed excellently well in capturing the overall variations in the IGS zenith delays at all the IGS sites in West Africa with an average MB, MAE, RMSE, $r, r^{2}, \mathrm{IA}_{\mathrm{r}}, \mathrm{NSE}$, and FAC2 of $0.38 \mathrm{~cm}, 0.87 \mathrm{~cm}$, $1.11 \mathrm{~cm}, 0.988,0.976,0.992,0.967$, and 1.00 (100\%), respectively. Additionally, the MCT further revealed that the performance of the VMF3-derived ZTD is not significantly different from that of the IGS-derived ZTD at 5\% significance level. Finally, on the basis of model performance evaluation criteria in $[57,64]$, we conclude that the VMF3 tropospheric product is sufficiently accurate to be used as an alternative ZTD data source to supplement the IGS tropospheric products just in case the IGS sites data are unattainable. The results of the analysis have also proven that the VMF3-ZTD data can be utilised as an independent data source to improve the continuous availability of ZTD data in West Africa, which can subsequently be used to provide continuous retrieval of PWV, a key parameter for meteorological applications, climate monitoring, and prediction in the region.

\section{Data Availability}

The IGS and VMF3 datasets used to support the findings of this study are available from the corresponding author upon request.

\section{Conflicts of Interest}

The authors declare that there are no conflicts of interest.

\section{Acknowledgments}

The authors wish to thank the Vienna Mapping Functions (VMF) and International GNSS Service (IGS) data centres for their open-access tropospheric delay products. 


\section{References}

[1] A. El-Rabbany, Introduction to GPS: The Global Positioning System, Artech House, Norwood, MA, USA, First edition, 2002.

[2] V. B. Mendes, "Modeling the neutral-atmospheric propagation delay in radiometric space techniques," Department of Geodesy and Geomatics Engineering Technical Report No. 199, p. 353, University of New Brunswick, Fredericton, New Brunswick, Canada, 1999.

[3] T. Nikolaidou, K. Balidakis, F. Nievinski, M. Santos, and H. Schuh, "Impact of different NWM-derived mapping functions on VLBI and GPS analysis," Earth, Planets and Space, vol. 70, no. 1, pp. 1-16, 2018.

[4] I. Sanlioglu and M. Zeybek, "Investigation on GPS heighting accuracy with use of tropospheric models in commercial GPS softwares for different heights," in Proceedings of the FIG working Week 2012, pp. 6-10, Rome, Italy, May 2012.

[5] M. Bevis, S. Businger, T. A. Herring, C. Rocken, R. A. Anthes, and R. H. Ware, "GPS meteorology: remote sensing of atmospheric water vapor using the Global Positioning System," Journal of Geophysical Research, vol. 97, no. D14, pp. 15787-15801, 1992.

[6] M. Bevis, S. Businger, S. Chiswell et al., "GPS meteorology: mapping zenith wet delays onto precipitable water," Journal of Applied Meteorology, vol. 33, no. 3, pp. 379-386, 1994.

[7] P. Jiang, S. Ye, D. Chen, Y. Liu, and P. Xia, "Retrieving precipitable water vapor data using GPS zenith delays and global reanalysis data in China," Remote Sensing, vol. 8, no. 5, p. 389, 2016.

[8] C. Jiang, T. Xu, S. Wang, W. Nie, and Z. Sun, "Evaluation of zenith tropospheric delay derived from ERA5 data over China using GNSS observations," Remote Sensing, vol. 12, no. 4, p. 663, 2020.

[9] K. Wilgan, W. Rohm, and J. Bosy, "Multi-observation meteorological and GNSS data comparison with Numerical Weather Prediction model," Atmospheric Research, vol. 156, pp. 29-42, 2015.

[10] C. Pikridas, S. Katsougiannopoulos, and N. Zinas, "A comparative study of zenith tropospheric delay and precipitable water vapor estimates using scientific GPS processing software and web based automated PPP service," Acta Geodaetica et Geophysica, vol. 49, no. 2, pp. 177-188, 2014.

[11] B. Hofmann-Wellenhof, H. Lichtenegger, and E. Wasle, GNSS-Global Navigation Satellite Systems GPS, Springer Vienna, New York, NY, USA, 2008.

[12] J. Saastamoinen, "Atmospheric correction for the troposphere and stratosphere in radio ranging satellites," The Use of Artificial Satellites for Geodesy, vol. 15, pp. 247-251, 1972.

[13] H. S. Hopfield, "Two-quartic tropospheric refractivity profile for correcting satellite data," Journal of Geophysical Research, vol. 74, no. 18, pp. 4487-4499, 1969.

[14] H. D. Black and A. Eisner, "Correcting satellite Doppler data for tropospheric effects," Journal of Geophysical Research, vol. 89, no. D2, pp. 2616-2626, 1984.

[15] R. F. Leandro, R. B. Langley, and M. C. Santos, "UNB3m_ pack: a neutral atmosphere delay package for radiometric space techniques," GPS Solutions, vol. 12, no. 1, pp. 65-70, 2008.

[16] N. Penna, A. Dodson, and W. Chen, "Assessment of EGNOS tropospheric correction model," Journal of Navigation, vol. 54, no. 1, pp. 37-55, 2001.
[17] D. Landskron and J. Böhm, "VMF3/GPT3: refined discrete and empirical troposphere mapping functions," Journal of Geodesy, vol. 92, no. 4, pp. 349-360, 2018.

[18] S. H. Byun, Y. E. Bar-sever, and G. Gendt, "The new tropospheric product of the international GNSS service," in Proceedings of the ION GNSS-2005 18th International Technical Meeting of the Satellite, pp. 241-249, Long Beach, CA, USA, September 2005.

[19] R. C. Ssenyunzi, B. Oruru, F. M. D’ujanga, E. Realini, and N. Van de Giesen, "Variability and accuracy of zenith total delay over the East African tropical region," Advances in Space Research, vol. 64, no. 4, 2019.

[20] M. Jgouta, B. Nsiri, and R. Marrakh, "Usage of a correction model to enhance the evaluation of the zenith tropospheric delay," International Journal of Applied Engineering Research, vol. 11, no. (6, pp. 4648-4654, 2016.

[21] Y. Asamoah and K. Ansah-Mensah, "Temporal description of annual temperature and rainfall in the Bawku area of Ghana," Advances in Meteorology, vol. 2020, Article ID 3402178, 18 pages, 2020.

[22] O. Bock, M. N. Bouin, E. Doerflinger et al., "West African Monsoon observed with ground-based GPS receivers during African Monsoon multidisciplinary analysis (AMMA)," Journal of Geophysical Research: Atmospheres, vol. 113, no. D21, 2008.

[23] A. Walpersdorf, M.-N. Bouin, O. Bock, and E. Doerflinger, "Assessment of GPS data for meteorological applications over Africa: study of error sources and analysis of positioning accuracy," Journal of Atmospheric and Solar-Terrestrial Physics, vol. 69, no. 12, pp. 1312-1330, 2007.

[24] O. A. Isioye, L. Combrinck, J. O. Botai, and C. Munghemezulu, "The potential for observing African weather with GNSS remote sensing," Advances in Meteorology, vol. 2015, Article ID 723071, 16 pages, 2015.

[25] S. Boutiouta and A. Lahcene, "Preliminary study of GNSS meteorology techniques in Algeria," International Journal of Remote Sensing, vol. 34, no. 14, pp. 5105-5118, 2013.

[26] E. Pottiaux, H. Namaoui, H. Brenot, S. Kahlouche, R. Van Malderen, and A. H. Belbachir, "GPS water vapor and its comparison with radiosonde and ERA-interim data in Algeria," Advances in Atmospheric Sciences, vol. 34, no. 5, pp. 623-634, 2017.

[27] O. A. Isioye, L. Combrinck, and J. O. Botai, "Retrieval and analysis of precipitable water vapour based on GNSS, AIRS, and reanalysis models over Nigeria," International Journal of Remote Sensing, vol. 38, no. 20, pp. 5710-5735, 2017.

[28] O. A. Isioye, L. Combrinck, and J. Botai, "Modelling weighted mean temperature in the West African region: implications for GNSS meteorology," Meteorological Applications, vol. 23, no. 4, pp. 614-632, 2016.

[29] A. A. Acheampong, C. Fosu, L. K. Amekudzi, and E. Kaas, "Comparison of precipitable water over Ghana using GPS signals and reanalysis products," Journal of Geodetic Science, vol. 5, no. 1, pp. 163-170, 2015.

[30] A. Acheampong and K. Obeng, "Application of GNSS derived precipitable water vapour prediction in West Africa," Journal of Geodetic Science, vol. 9, no. 1, pp. 41-47, 2019.

[31] R. C. Ssenyunzi, B. Oruru, F. M. D’ujanga et al., "Performance of ERA5 data in retrieving precipitable water vapour over East african tropical region," Advances in Space Research, vol. 65, no. 8, pp. 1877-1893, 2020.

[32] W. Suparta and K. M. Alhasa, "Application of ANFIS model for prediction of zenith tropospheric delay," in Proceedings of the 2013 3rd International Conference on Instrumentation, 
Communications, pp. 172-177, Bandung, Indonesia, November 2013.

[33] L. Urquhart, M. C. Santos, F. G. Nievinski, and J. Böhm, "Generation and assessment of VMF1-type grids using northAmerican numerical weather models," International Association of Geodesy Symposia, vol. 139, pp. 3-9, 2014.

[34] Y. Yao, X. Xu, C. Xu, W. Peng, and Y. Wan, "GGOS tropospheric delay forecast product performance evaluation and its application in real-time PPP," Journal of Atmospheric and Solar-Terrestrial Physics, vol. 175, no. 2018, pp. 1-17, 2018.

[35] Y. Yao, X. Xu, and Y. Hu, "Precision analysis of GGOS tropospheric delay product and its application in PPP," Acta Geodaetica et Cartographica Sinica, vol. 46, no. 3, pp. 278-287, 2017.

[36] J. Li, L. Liu, L. Huang, S. Xie, F. Chen, and L. Liu, “Assessment of the zenith tropospheric delay derived from GGOS Atmosphere data with GNSS ZTD over China," in Proceedings of the Fifth Recent Advances in Quantitative Remote Sensing, Torrent, Spain, Sepetmebr 2018.

[37] Y. Yuan, L. Holden, A. Kealy, S. Choy, and P. Hordyniec, "Assessment of forecast Vienna mapping function 1 for realtime tropospheric delay modeling in GNSS," Journal of Geodesy, vol. 93, pp. 1501-1514, 2019.

[38] N. Putri, D. Landskron, and J. Böhm, “Assessing the performance of Vienna mapping functions 3 for GNSS stations in Indonesia using precise point positioning," Advances in Geosciences, vol. 50, pp. 77-86, 2020.

[39] P. Meunram and C. Satirapod, "Spatial variation of precipitable water vapor derived from GNSS CORS in Thailand," Geodesy and Geodynamics, vol. 10, no. 2, pp. 140-145, 2019.

[40] H. Zhang, Y. Yuan, W. Li, Y. Li, and Y. Chai, "Assessment of three tropospheric delay models (IGGtrop, EGNOS and UNB3m) based on precise point positioning in the Chinese region," Sensors, vol. 16, no. 1, p. 122, 2016.

[41] S. A.-M. Younes, "Modeling investigation of wet tropospheric delay error and precipitable water vapor content in Egypt," The Egyptian Journal of Remote Sensing and Space Science, vol. 19, no. 2, pp. 333-342, 2016.

[42] J. Sanz, J. M. Juan, and M. Hernández-Pajares, "GNSS data processing," in Proceedings of the Fundamentals and Algorithms, Noordwijk, Netherlands, May 2013.

[43] F. Kleijer, Troposphere Modeling and Filtering for Precise GPS Leveling, Nederlandse Comissie voor Geodesie, Delft, Netherlands, 2004.

[44] E. K. Smith and S. Weintraub, "The constants in the equation for atmospheric refractive index at radio frequencies," Journal of Research of the National Bureau of Standards, vol. 50, no. 1, pp. 39-41, 1953.

[45] V. Nafisi, L. Urquhart, M. C. Santos et al., "Comparison of ray-tracing packages for troposphere delays," IEEE Transactions on Geoscience and Remote Sensing, vol. 50, no. 2, pp. 469-481, 2012.

[46] K. Wilgan and A. Geiger, "High-resolution models of tropospheric delays and refractivity based on GNSS and numerical weather prediction data for alpine regions in Switzerland," Journal of Geodesy, vol. 93, no. 6, pp. 819-835, 2019.

[47] Y. Hu and Y. Yao, "A new method for vertical stratification of zenith tropospheric delay," Advances in Space Research, vol. 63, no. 9, pp. 2857-2866, 2019.

[48] Y. Lou, J. Huang, W. Zhang, H. Liang, F. Zheng, and J. Liu, “A new zenith tropospheric delay grid product for real-time PPP applications over China," Sensors, vol. 18, no. 2, pp. 65-14, 2018.
[49] Q. Chen, S. Song, S. Heise, Y.-A. Liou, W. Zhu, and J. Zhao, "Assessment of ZTD derived from ECMWF/NCEP data with GPS ZTD over China," GPS Solutions, vol. 15, no. 4, pp. 415-425, 2011.

[50] J. Askne and H. Nordius, "Estimation of tropospheric delay for microwaves from surface weather data," Radio Science, vol. 22, no. 3, pp. 379-386, 1987.

[51] J. Boehm, J. Kouba, and H. Schuh, "Forecast Vienna mapping functions 1 for real-time analysis of space geodetic observations," Journal of Geodesy, vol. 83, no. 5, pp. 397-401, 2009.

[52] C. J. Willmott, S. M. Robeson, and K. Matsuura, "A refined index of model performance," International Journal of Climatology, vol. 32, no. 13, p. 2088, 2011.

[53] M. H. Ali and I. Abustan, "A new novel index for evaluating model performance," The Journal of Natural Resources and Development, vol. 4, no. 1, pp. 1-9, 2014.

[54] A. S. Sayegh, S. Munir, and T. M. Habeebullah, "Comparing the performance of statistical models for predicting PM10 concentrations," Aerosol and Air Quality Research, vol. 14, no. 3, pp. 653-665, 2014.

[55] J. E. Nash and J. V. Sutcliffe, "River flow forecasting through conceptual models part I-a discussion of principles," Journal of Hydrology, vol. 10, no. 3, pp. 282-290, 1970.

[56] D. G. Fox, "Judging air quality model performance: a summary of the AMS workshop on dispersion model performance, woods hole, mass," Bulletin of the American Meteorological Society, vol. 62, no. 5, pp. 599-609, 1981.

[57] F. Chiew and T. McMahon, "Assessing the adequacy of catchment streamflow yield estimates," Soil Research, vol. 31, no. 5, pp. 665-680, 1993.

[58] D. R. Legates and G. J. Mccabe, "A refined index of model performance: a rejoinder," International Journal of Climatology, vol. 33, no. 4, pp. 1053-1056, 2013.

[59] J. C. Chang and S. R. Hanna, "Air quality model performance evaluation," Meteorology and Atmospheric Physics, vol. 87, no. 1-3, pp. 167-196, 2004.

[60] M. L. McHugh, "Multiple comparison analysis testing in ANOVA," Biochemia Medica, vol. 21, no. 3, pp. 203-209, 2011.

[61] S. Lee and D. K. Lee, "What is the proper way to apply the multiple comparison test?" Korean Journal of Anesthesiology, vol. 71, no. 5, pp. 353-360, 2018.

[62] P. Schober, C. Boer, and L. A. Schwarte, "Correlation coefficients," Anesthesia \& Analgesia, vol. 126, no. 5, pp. 1763-1768, 2018.

[63] J. Frost, Regression Analysis: An Intuitive Guide for Using and Interpreting Linear Models, Statistics by Jim Publishing, State, College, PA, USA, 2019.

[64] D. N. Moriasi, M. W. Gitau, N. Pai, and P. Daggupati, "Hydrologic and water quality models: performance measures and evaluation criteria," Transactions of the ASABE, vol. 58, no. 6, pp. 1763-1785, 2015.

[65] K. E. Taylor, "Summarizing multiple aspects of model performance in a single diagram," Journal of Geophysical Research: Atmospheres, vol. 106, no. D7, pp. 7183-7192, 2001. 